\title{
Honeywell
}

\section{Developing the Manufacturing Process for VCE: Binder for Filled Elastomers}

Federal Manufacturing \& Technologies

\author{
E.A. Eastwood
}

KCP-613-8681

November 2009

Final Report

Approved for public release; distribution is unlimited.

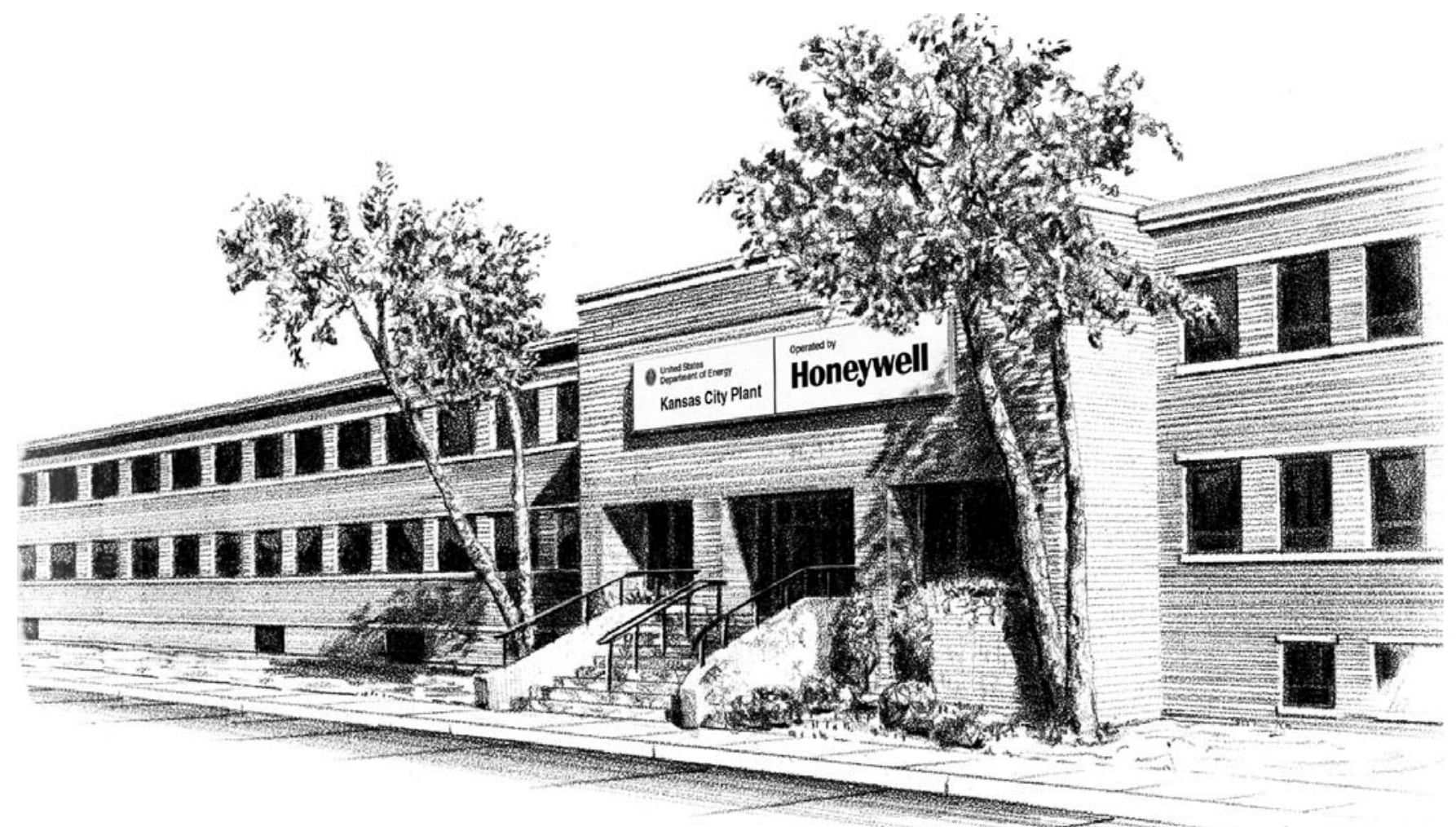

Prepared under prime contract DE-ACO4-01AL66850 for the United States Department of Energy 


\section{DISCLAIMER}

This report was prepared as an account of work sponsored by an agency of the United States Government. Neither the United States Government nor any agency thereof, nor any of their employees, makes any warranty, express or implied, or assumes any legal liability or responsibility for the accuracy, completeness, or usefulness of any information, apparatus, product, or process disclosed, or represents that its use would not infringe privately owned rights. Reference herein to any specific commercial product, process or service by trade names, trademark, manufacturer, or otherwise, does not necessarily constitute or imply its endorsement, recommendation or favoring by the United States Government or any agency thereof. The views and opinions of authors expressed herein do not necessarily state or reflect those of the United States Government or any agency thereof.

All data prepared, analyzed and presented has been developed in a specific context of work and was prepared for internal evaluation and use pursuant to that work authorized under the reference contract. Reference herein to any specific commercial product, process or service by trade name, trademark, manufacturer, or otherwise, does not necessarily constitute or imply its endorsement, recommendation or favoring by the United States Government, any agency thereof or Honeywell Federal Manufacturing \& Technologies, LLC.

Printed in the United States of America.

This report has been reproduced from the best available copy.

Available to DOE and DOE contractors from the Office of Scientific and Technical Information, P.O. Box 62, Oak Ridge, Tennessee 37831; prices available from (865) 576-8401, FTS 626-8401.

Available to the public from the National Technical Information Service, U.S. Department of Commerce, 5285 Port Royal, Rd., Springfield, Virginia 22161, (703) 487-4650.

A prime contractor with the United States Department of Energy under Contract Number DE-AC04-O1AL66850

\author{
Honeywell Federal Manufacturing \& Technologies \\ P.O. Box 419159 \\ Kansas City, Missouri, 64141-6159
}




\title{
Honeywell
}

KCP-613-8681

Distribution Category UC-42

Approved for public release; distribution is unlimited.

Developing the Manufacturing Process for VCE:

Binder for Filled Elastomers

\author{
E. A. Eastwood
}

November 2009

Final Report

E. A. Eastwood, Project Leader 



\section{Contents}

Section Page

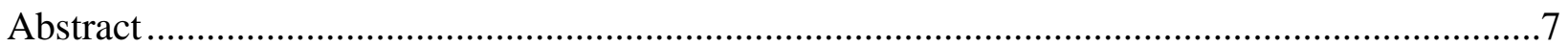

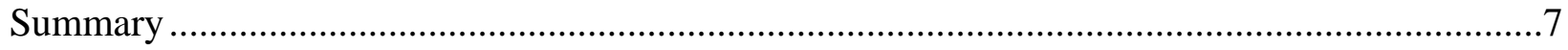

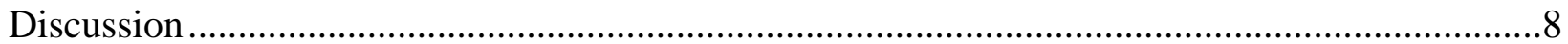

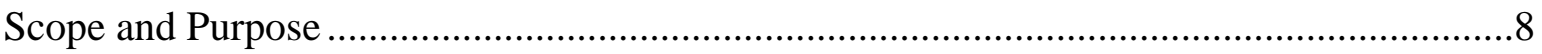

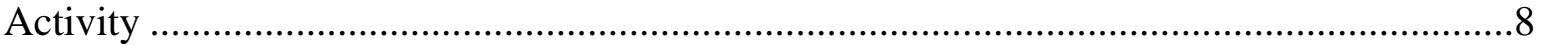

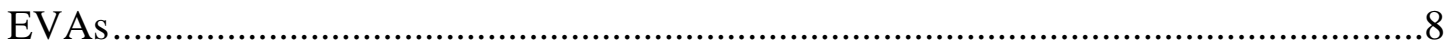

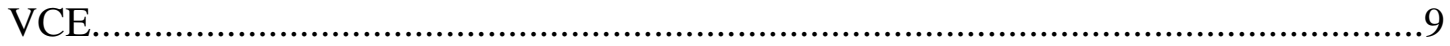

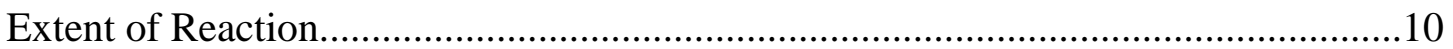

Equipment and Process Modifications...............................................................14

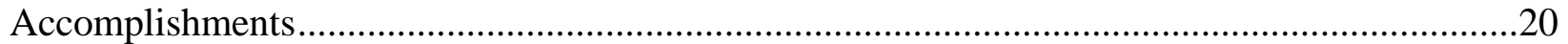

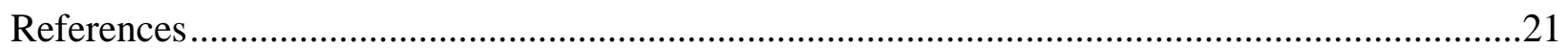




\section{Illustrations}

Figure Page

1 EVA, Poly(ethylene-co-vinyl acetate) copolymer ....................................................

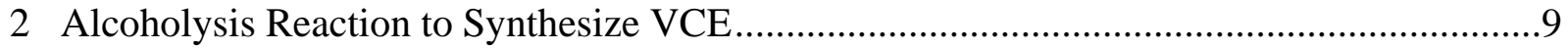

3 VCE, Poly(ethylene-co-vinyl acetate-co-vinyl alcohol) erpolymer .................................9

4 Plot of Tydroxyl Contents as a Function of Time at Varying Reaction Temperatures ........11

5 Conversion Rate $(\mathrm{OH} \% / \mathrm{hr})$ as a Function Temperature for Reactions Completed in 2L,

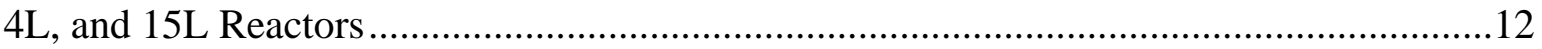

6 Hydroxyl Conversion Rates for Both the Small Scale and 50 Gallon Batches ...................13

7 Nutsche Filter Dryer Purchased From Pfaudler.........................................................15

8 Drying Trays With and Without Expanded Metal Covers.............................................16

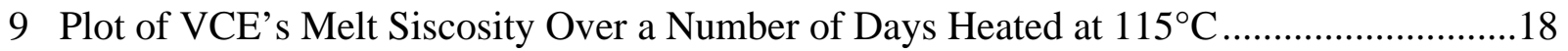

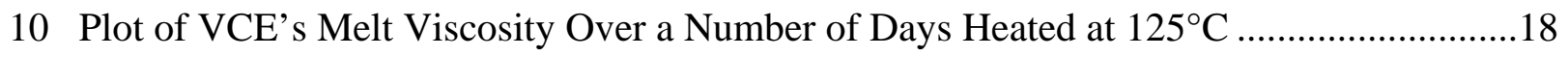

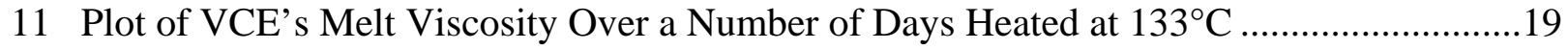

12 Plot Showing Length of Time to Form a Solid VCE Sheet at Various Temperatures .........19

\section{Tables}

Table

Page

1 Solvent Formulation for VCE Reactions. .............................................................

2 Batches of VCE Using 50 Gallon Reactor...................................................................12

3 Reaction Time at Different Reactor Temperatures ......................................................14 


\begin{abstract}
This topical report presents work completed to re-establish the manufacturing process for poly(ethylene-co-vinyl acetate-co-vinyl alcohol) terpolymer called VCE. The new VCE formulations meet the material requirements and have lower melt viscosity, which results in improved production for the next assembly. In addition, the reaction conditions were optimized in order to achieve a satisfactory conversion rate to enable production in a single work shift. Several equipment and process changes were made to yield a manufacturing process with improved product quality, yield, efficiency, and worker safety.
\end{abstract}

\title{
Summary
}

This report details efforts to re-establish the in-house capability to manufacture poly(ethyleneco-vinyl acetate-co-vinyl alcohol) in the Polymer Production Facility at the Kansas City Plant (KCP). This elastomeric material is used as a binder for filled elastomer products and commonly called VCE, which is an acronym for vinyl copolymer elastomer. Several lessons learned during this development are described within this report. The ratio of starting materials including two EVAs, toluene, methanol, and ethanol are given and a description of the reaction and composition requirements (initial and final) is discussed. There are a number of factors that control the extent of reaction and ultimately the VCE composition. The amount of base (4.62 pbw $0.44 \mathrm{~N}$ potassium hydroxide), the reaction temperature (varied from 80 to $100{ }^{\circ} \mathrm{F}$ ), and the reaction time (dependant on temperature) are all variables that were discussed and optimized. Higher reaction temperatures result in faster conversions and a conversion rate $(\mathrm{OH} \% / \mathrm{hr})$ as a function temperature equation was developed based on reactions at varying temperatures and times. Initially, an equation was found for reactions done on 2L, 4L, and 15L reactors; however, when completed in a 50 gallon reactor, the observed conversion rate was faster. After a number of reactions were completed at the 50 gallon scale, a new conversion rate based on temperature equation was found and given below (for a nominal 1.5\% hydroxyl content VCE).

$$
\text { Reaction Time }=1.5 /\left[\left(0.0535 \times \text { Temperature in }{ }^{\circ} \mathrm{F}\right)-4.5103\right]
$$

There were several equipment modifications and other changes to the manufacturing processes that were implemented. A Nutsche Filter Dryer was used as a precipitation vessel to recover and filter the VCE product, which resulted in a dramatically reduced worker exposure to chemical emissions, improving safety. A filter was inserted between the reaction reactor and the Nutsche Filter Dryer/precipitation vessel to remove contamination and improved product quality. Drying trays were redesigned to yield VCE sheets that were 8”x12”, which were much easier to handle and package. The amount of methanol used to precipitate the product was increased to improve efficiency and product recovery yield. For each 50 gallon reaction, three precipitations steps were completed using 55 gallons of methanol per precipitation or a total 165 gallons. Finally, a study was completed to determine the optimum time and temperature during the vacuum drying step. The optimum vacuum drying temperature was $245+/-15^{\circ} \mathrm{F}$, which requires 5 to 8 days to form a uniform solid sheet of VCE with these temperature range. 


\section{Discussion}

\section{Scope and Purpose}

In-house capability to manufacture poly(ethylene-co-vinyl acetate-co-vinyl alcohol) was developed at KCP. This elastomeric material is used as a binder for filled elastomer products and commonly called VCE, which is an acronym for vinyl copolymer elastomer. A scaled up manufacturing process for VCE was developed in the Polymer Production Facility. This report documents the lessons learned during this development and describe in greater detail the current manufacturing process.

\section{Activity}

\section{$\underline{\text { EVAs }}$}

VCE is made from poly(ethylene-co-vinyl acetate) or EVA (Figure 1) as the base starting material. Per the material specification, the initial composition of the EVA starting material is required to have a vinyl acetate content equal to $42 \pm 1 \%$, thus the ethylene content is $58 \pm 1 \%$. It was extremely difficult to find a commercially available EVA with this exact formulation; therefore, two EVAs were blended together to achieve the required composition. The original EVAs used to make VCE are no longer commercially available and thus alternates were needed. Previous reports have documented extensive characterization data for candidate replacement EVAs. ${ }^{1,2}$ The first replacement formulation developed used Levamelt ${ }^{\circledR} 1$ (44\% vinyl acetate and $56 \%$ ethylene) purchased from Lanxess Corporation at 65 parts by weight (pbw) and blended with 35 pbw Evatane ${ }^{\circledR} 1-2$ (38\% vinyl acetate and 62\% ethylene) purchased from Arkema Inc. This formulation was designed to give similar material properties to the original VCE material. Prior to scaling up this formulation, it became desirable have a VCE material with a lower melt viscosity to aid production of filled elastomer parts. ${ }^{2}$ Therefore, a second formulation was developed that yielded VCE with a much lower melt viscosity. Evatane ${ }^{\circledR} 1-2$ was replaced with a lower molecular weight EVA, Evatane ${ }^{\circledR} 3-4$, also purchased from Arkema Inc. A formulation of 19 pbw Evatane ${ }^{\circledR}$ 3-4 and 81 pbw Levamelt ${ }^{\circledR} 1$ were used to make replacement VCE. Extensive characterization studies and exact reaction details are reported previously. ${ }^{2}$

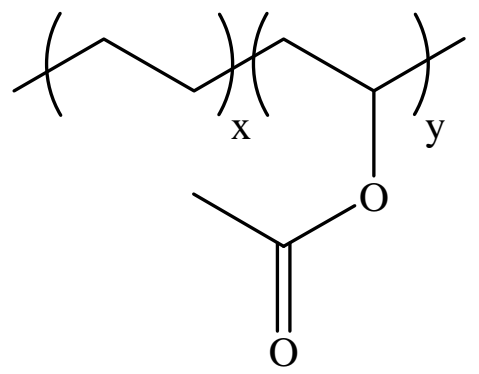

Figure 1. EVA, poly(ethylene-co-vinyl acetate) copolymer 


\section{VCE}

The EVAs are dissolved in the toluene in the presence of methanol and ethanol by the ratios given in Table 1. Base is then added to the solution, causing the material to undergo partial hydrolysis by a saponification reaction. A small percentage of the acetate groups are converted into alcohol groups as shown in Figure $2 .^{2-4}$ The solution is allowed to react until the correct vinyl acetate or hydroxyl content is reached, after which the solution is neutralized with acid.

\begin{tabular}{|c|c|}
\hline Material & Parts By Weight \\
\hline EVAs & 100 \\
\hline Toluene & 250 \\
\hline Ethanol & 45.4 \\
\hline Methanol & 45.4 \\
\hline
\end{tabular}

Table 1. Solvent Formulation for VCE Reactions

EVA<smiles>[X]C(C)(CCC(C)(C)C)CC(OC(C)=O)C([Y])(C)C</smiles>

poly(ethylene-co-vinyl acetate)

$$
\begin{gathered}
\begin{array}{c}
\text { methanol, ethanol, } \\
\text { toluene, } \mathrm{KOH}
\end{array} \\
\underset{\begin{array}{c}
\text { alcoholysis } \\
\text { reaction }
\end{array}}{\longrightarrow}
\end{gathered}
$$

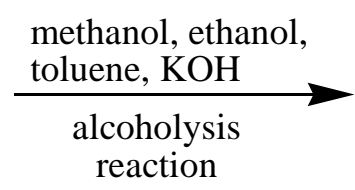

poly(ethylene-co-vinyl acetate-co-vinyl alcohol)

\section{VCE}

Figure 2. Alcoholysis Reaction to Synthesize VCE

The resulting poly(ethylene-co-vinyl acetate-co-vinyl alcohol) terpolymer or VCE (Figure 3) is required to have a hydroxyl content of $1.5 \pm 0.5 \%$. The two requirements (42\% vinyl acetate for the starting EVAs and 1.5\% hydroxyl content of VCE) could yield a number of conforming compositions but nominally the VCE composition consists of 58\% ethylene, 36\% vinyl acetate, and 6\% vinyl alcohol.<smiles>[Y]C(CC(C)(C)C)C(CC(C)(C)C)OC(C)=O</smiles>

Figure 3. VCE, poly(ethylene-co-vinyl acetate-co-vinyl alcohol) terpolymer 


\section{Extent of Reaction}

There are a number of factors that control the extent of reaction and ultimately the resulting vinyl acetate and hydroxyl contents of the final VCE product. The amount of potassium hydroxide $(\mathrm{KOH})$ added, the reaction temperature, and the reaction time are all variables that can effect the final VCE composition.

\section{Potassium Hydroxide/KOH}

\section{KOH Concentration}

The original process engineering specification for manufacturing VCE reportedly used a $0.5 \mathrm{~N}$ alcoholic $\mathrm{KOH}$ to initiate the reaction. ACS reagent grade $\mathrm{KOH}$ was dissolved in "mostly" equal volumes of ethanol and methanol. To make a 1 liter solution the following procedure was used: $500 \mathrm{~mL}$ of methanol was added into a $1000 \mathrm{~mL}$ volumetric flask, add $28.05 \mathrm{~g}$ of $\mathrm{KOH}$ pellets, and finally add ethanol until the $1000 \mathrm{~mL}$ volume was reached ( 500 mL). The ACS reagent grade $\mathrm{KOH}$ has a minimum purity of $85 \%$. $\mathrm{KOH}$ is extremely hygroscopic and the majority of the impurities present is mostly water. It was not realized that the purity was significantly lower than $100 \%$ when the solutions were first being prepared and the target composition of $0.5 \mathrm{~N}$ $\mathrm{KOH}$ was not achieved. The actual, measured normality using the above process gave a normality of 0.44 , which correlates to approximately $88 \%$ purity. Several initial experiments were completed using $0.44 \mathrm{~N} \mathrm{KOH}$ and rather than repeat those experiments, the $\mathrm{KOH}$ normality was kept at $\sim 0.44 \mathrm{~N}$ for production batches.

\section{KOH Amount}

In the past, the manufacturing process used 1.54 parts by weight (pbw) $0.5 \mathrm{~N} \mathrm{KOH}$ per $100 \mathrm{pbw}$ EVAs and reacted for 3 to 4 hours. However, when this amount $(0.44 \mathrm{~N} \mathrm{KOH})$ and reaction time was used with replacement EVAs, hydroxyl conversion rates were very low $(\mathrm{OH} \%=0.5 \%)$. However, the reaction temperature of the historical batches was not known and the temperature of this lab-scale reaction was $84^{\circ} \mathrm{F}$. The amount of $\mathrm{KOH}$ was doubled to 3.08 pbw per 100 pbw EVAs and the reaction was extended to 6 to 6.5 hours. Again, the reaction temperature used was $84^{\circ} \mathrm{F}$. By doubling the $\mathrm{KOH}$, higher hydroxyl contents were achieved, but the resulting VCE product just barely met the hydroxyl content $(\mathrm{OH} \%=1.0 \%)$. By using 3.08 pbw of the KOH solution, longer reaction times would most likely yield VCE with hydroxyl contents closer to the middle of the specification range. However, longer reaction times would substantially surpass the normal 8 hour work shift. Therefore, the amount of $0.44 \mathrm{~N} \mathrm{KOH}$ added to the reaction was increased further to 4.62 pbw (tripled) and gave much faster reactions, which could more easily achieve the $1.5 \%$ hydroxyl contents within a normal work shift.

\section{Reaction Temperature and Time}

Several VCE batches with the replacement formulation were synthesized at varying temperatures $\left(80-100^{\circ} \mathrm{F}\right)$ in $2 \mathrm{~L}, 4 \mathrm{~L}$, and $15 \mathrm{~L}$ scale reactors. The formulation of 19 pbw Evatane ${ }^{\circledR} 3-4$ and 81 pbw Levamelt ${ }^{\circledR} 1$ were mixed together with toluene, methanol, and ethanol mixture, per the ratios given in Table 1. 4.62 pbw $0.44 \mathrm{~N} \mathrm{KOH}$ was added the dissolved EVAs to initiate the 
reaction. The reactions were allowed to react and then stopped by adding $2.0 \mathrm{~N}$ methanolic $\mathrm{HCl}$ solution, which neutralized the reaction. Several reactions were completed in $2 \mathrm{~L}$ and $4 \mathrm{~L}$ reactors with no external heat added, however, there was some heat added by the stirring the reaction and the measured reaction temperatures were $82-84^{\circ} \mathrm{F}$. A jacketed $15 \mathrm{~L}$ reactor was used to complete two reactions at slightly elevated temperatures $93^{\circ} \mathrm{F}$ and $100^{\circ} \mathrm{F}$.

The hydroxyl contents are plotted as a function of reaction time for these reactions in Figure 4 for the lab scale batches. Higher reaction temperatures resulted in faster hydroxyl conversion rates. The slopes from each temperature plot correlates to the hydroxyl conversion rate (OH\%/hour). The conversion rates were then plotted as a function of temperature in Figure 5. From the slope in Figure 5, an equation can be used to determine the correct reaction time for a specific temperature and desired hydroxyl content (1.5\%). This equation is as follows:

$$
\text { Reaction Time }=
$$

$\overline{\left[\left(0.0232 \times \text { Temperature in }{ }^{\circ} \mathrm{F}\right)-1.6404\right]}$

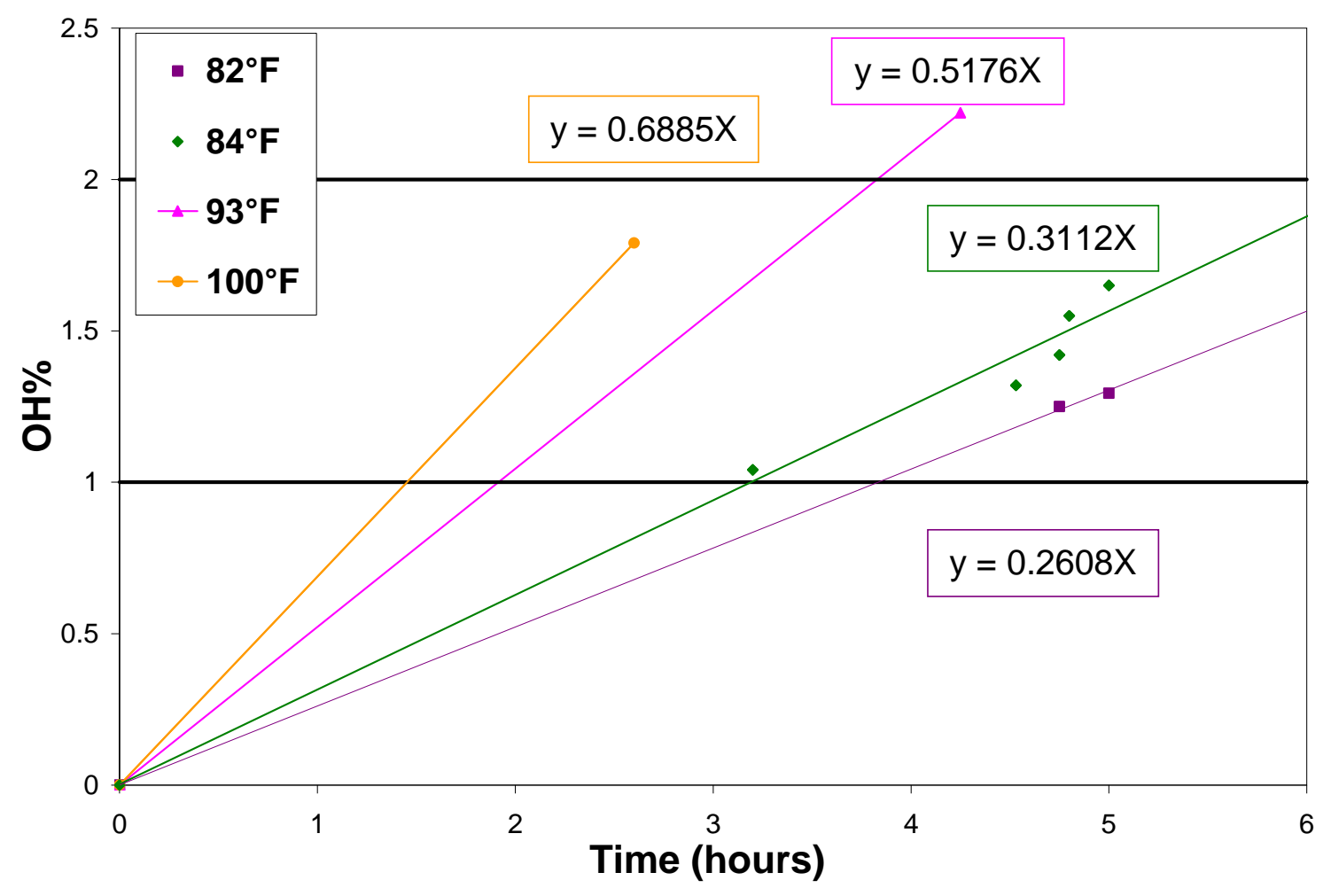

Figure 4: Plot of Hydroxyl Contents as a Function of Time at Varying Reaction Temperatures 


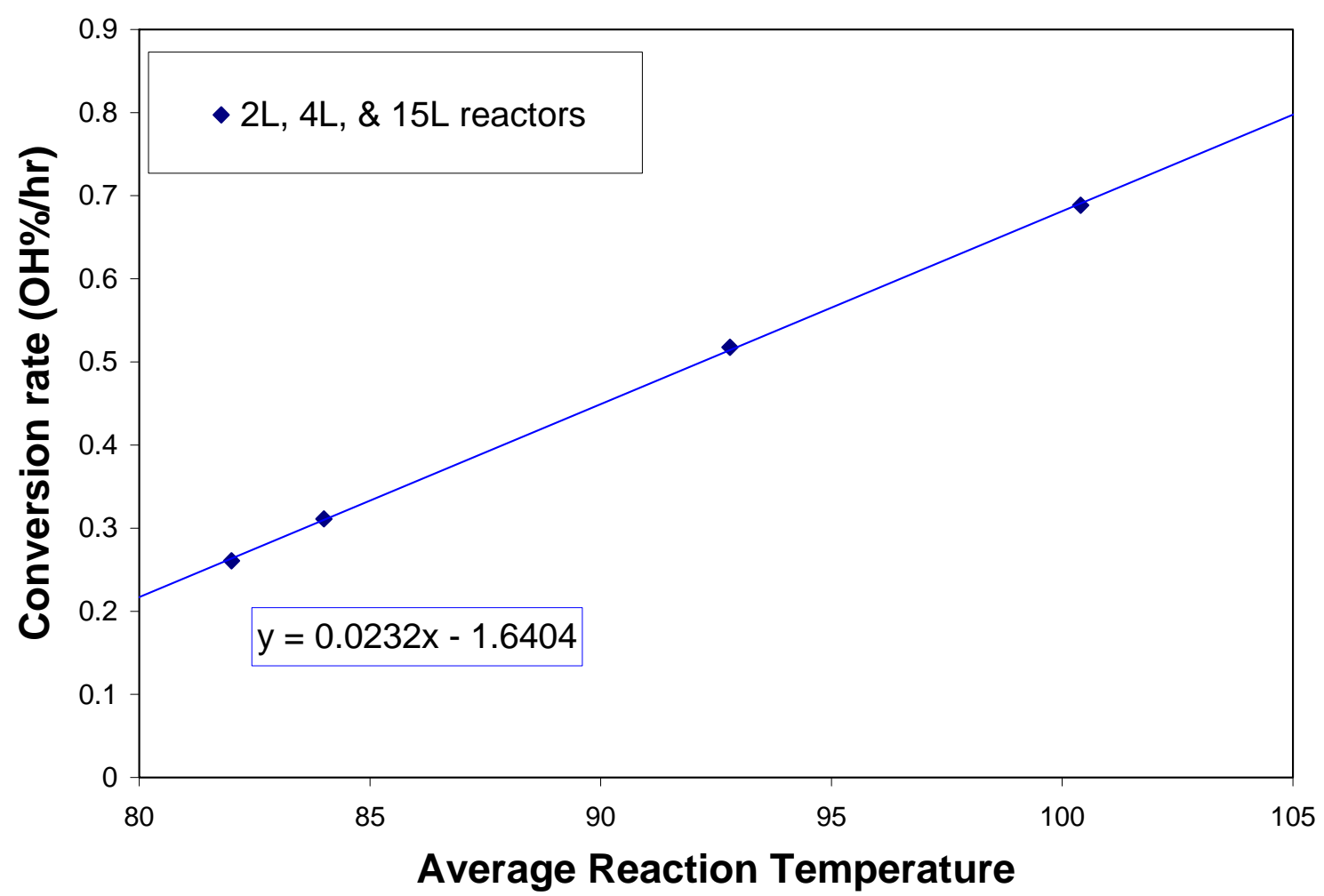

Figure 5: Conversion rate $(\mathrm{OH} \% / \mathrm{hr})$ as a Function Temperature for Reactions Completed in 2L, 4L, and 15L Reactors

\section{Batch Size}

The lessons learned from the $2 \mathrm{~L}$, 4L, and 15L lab-scale reactions were used to manufacture VCE using a 50 gallon reactor with a target batch size of 72.5 pounds. The target temperature for these 50 gallon batches was $100 \pm 2^{\circ} \mathrm{F}$. During the reactions, the temperatures fluctuated $\pm 1^{\circ} \mathrm{F}$. The reaction details of seven full scale production lots completed are shown in Table 2.

\begin{tabular}{|c|c|c|c|c|c|c|c|}
\hline Lot & VAi & VAf & OH\% & time & OH\%/hr & $\begin{array}{c}\text { Average } \\
\text { Temperature }\end{array}$ & $\begin{array}{c}\text { Maximum } \\
\text { Temperature }\end{array}$ \\
\hline 1 & 42.0 & 35.0 & 1.74 & 2.43 & 0.717 & 98.0 & 98.5 \\
\hline 2 & 42.0 & 35.0 & 1.74 & 2.00 & 0.870 & 101.0 & 101.3 \\
\hline 3 & 42.0 & 35.1 & 1.71 & 1.75 & 0.980 & 102.0 & 102.7 \\
\hline 4 & 42.6 & 36.9 & 1.44 & 1.83 & 0.785 & 99.5 & 100.0 \\
\hline 5 & 42.0 & 36.2 & 1.44 & 1.80 & 0.799 & 99.5 & 101.2 \\
\hline 6 & 42.1 & 36.0 & 1.53 & 2.15 & 0.713 & 97.5 & 98.8 \\
\hline 7 & 42.0 & 35.8 & 1.55 & 2.13 & 0.727 & 97.4 & 98.2 \\
\hline
\end{tabular}

Table 2. Batches of VCE Using 50 Gallon Reactor 
It was quickly realized the hydroxyl conversion rate was much faster in the 50 gallon reactor than what was observed with the small scale batches. The first two batches (lots 1 and 2) had hydroxyl contents equal to $1.74 \%$ even though the target hydroxyl content for the reaction was $1.50 \%$. By using the equation based on $2 \mathrm{~L}, 4 \mathrm{~L}$, and $15 \mathrm{~L}$ reactions (Conversion Rate $=.0232$ Temperature in ${ }^{\circ} \mathrm{F}-1.6404$ ), VCE product which met the VA\% and $\mathrm{OH} \%$ requirements was still able to be made. Figure 6 shows the conversion rate for both the small scale batches and faster 50 gallon batches. A more appropriate equation to determine the correct reaction time (endpoint) for 50 gallon reactions at a specific temperature and desired $\mathrm{OH}$ content (1.50) is given by the following equation.

Reaction Time $=$ 1.5 $\left[\left(0.0535 \mathrm{x}\right.\right.$ Temperature in $\left.\left.{ }^{\circ} \mathrm{F}\right)-4.5103\right]$

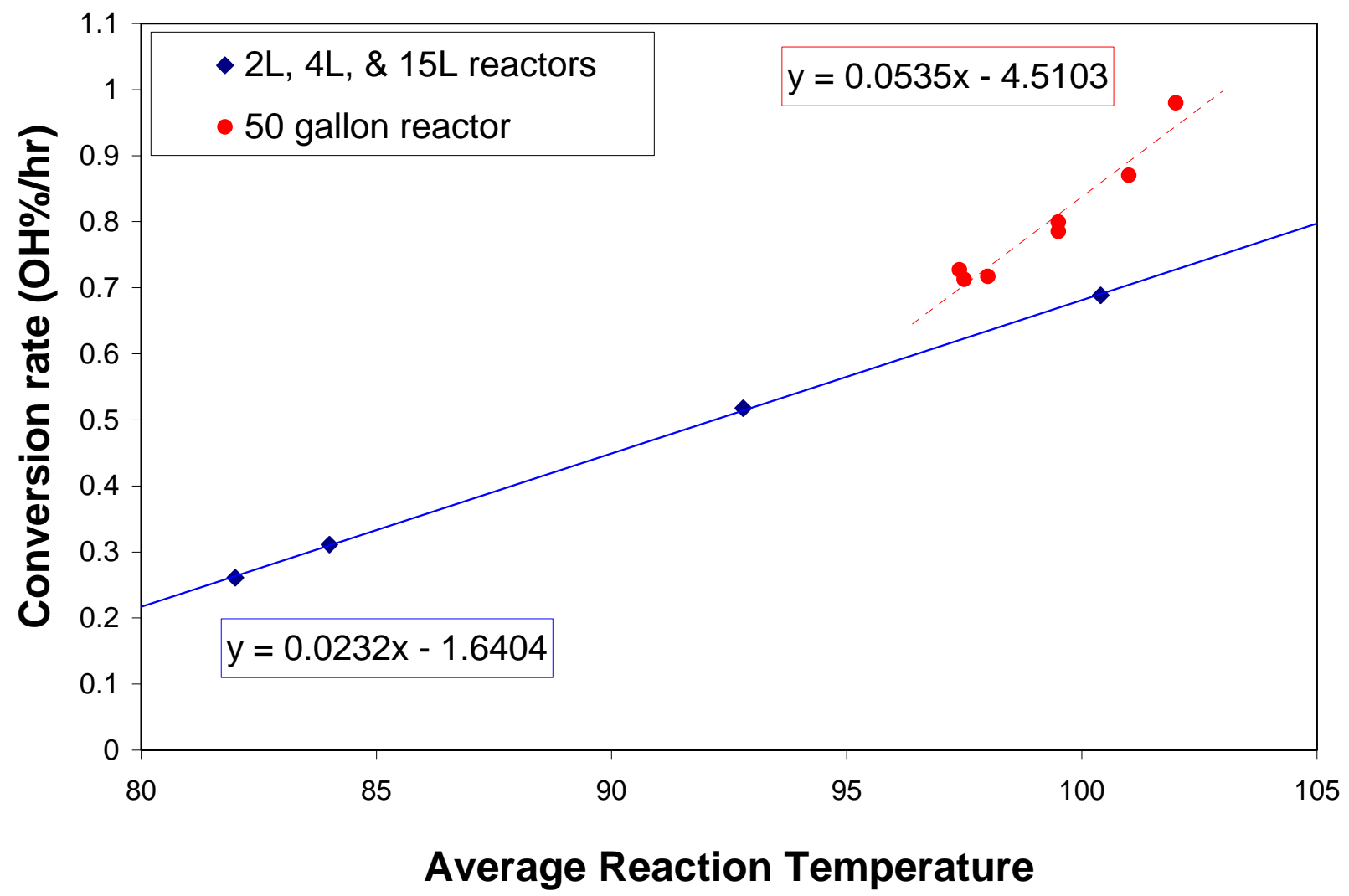

Figure 6. Hydroxyl Conversion Rates for Both the Small Scale and 50 Gallon Batches

The work instructions for the actual production batches recommends a reactor temperature of $100+5 /-7^{\circ} \mathrm{F}$. The required amount of $\mathrm{KOH}$ is added the reaction is stirred for approximately 82 to 195 minutes. The actual reaction time used will be based on engineering judgment with relationship to individual lots of EVA and guidelines given in Table 3. Table 3 provides reaction times based on the conversion rates at different average reactor temperatures. The target reaction times should be within $+/-10$ minutes of Table 3 . 


\begin{tabular}{|c|c|}
\hline $\begin{array}{c}\text { Average Reactor } \\
\text { Temperature }\left({ }^{\circ} \mathbf{F}\right)\end{array}$ & $\begin{array}{c}\text { Target Reaction } \\
\text { Time (minutes) }\end{array}$ \\
\hline $93^{\circ} \mathrm{F}$ & 195 minutes \\
\hline $94^{\circ} \mathrm{F}$ & 175 minutes \\
\hline $95^{\circ} \mathrm{F}$ & 158 minutes \\
\hline $96^{\circ} \mathrm{F}$ & 145 minutes \\
\hline $97^{\circ} \mathrm{F}$ & 133 minutes \\
\hline $98^{\circ} \mathrm{F}$ & 123 minutes \\
\hline $99^{\circ} \mathrm{F}$ & 115 minutes \\
\hline $100^{\circ} \mathrm{F}$ & 108 minutes \\
\hline $101^{\circ} \mathrm{F}$ & 101 minutes \\
\hline $102^{\circ} \mathrm{F}$ & 95 minutes \\
\hline $103^{\circ} \mathrm{F}$ & 90 minutes \\
\hline $104^{\circ} \mathrm{F}$ & 86 minutes \\
\hline $105^{\circ} \mathrm{F}$ & 82 minutes \\
\hline
\end{tabular}

Table 3. Reaction Time at Different Reactor Temperatures

\section{Equipment and Process Modifications}

There were several equipment modifications and other changes to the manufacturing processes that were implemented in order to either improve worker safety, quality, yield, or efficiency. Those process changes include use of a Nutsche Filter Dryer, incorporation of various filters, methanol amounts, new drying trays, and optimization of drying temperature and time.

\section{Nutsche Filter Dryer}

The historical manufacturing processes generated excess chemical emissions; therefore, the process was re-designed to use additional equipment to improve worker safety. The excess chemical emissions are due to large amounts of solvents (toluene, methanol, and ethanol) used for the reaction and product recovery. A Nutsche Filter Dryer/vessel was procured, installed, and integrating into the VCE manufacturing process. The Nutsche Filter Dryer was purchased from Pfaudler in December 2004 and installed in 2005. This vessel is capable of agitation, precipitation, filtration, washing, and drying organic and polymeric materials and is shown in Figure 7. After the reaction to form VCE is completed in a 50 gallon reactor, the VCE product is recovered in multiple precipitation steps using the Nutsche Filter Dryer. Dissolved VCE product is transferred to the Nutsche Filter Dryer for precipitation into methanol. Then while in the Nutsche Filter Dryer, the VCE product is washed and filtered. This versatile piece of equipment limits exposure of workers to solvent vapors; thus giving much safer processes. Also, filtration capacity has increased and time handling material greatly reduced. The Nutsche Filter Dryer was equipped with a 250 micron polypropylene filter for the first two full scale VCE batches. Some 
of the material was being lost through the filter; therefore a 100 micron stainless steel filter was used in subsequent batches which resulted in better filtering during the VCE recovery steps. By incorporating the Nutsche Filter Dryer, a closed production process was used to safely manufacture VCE.

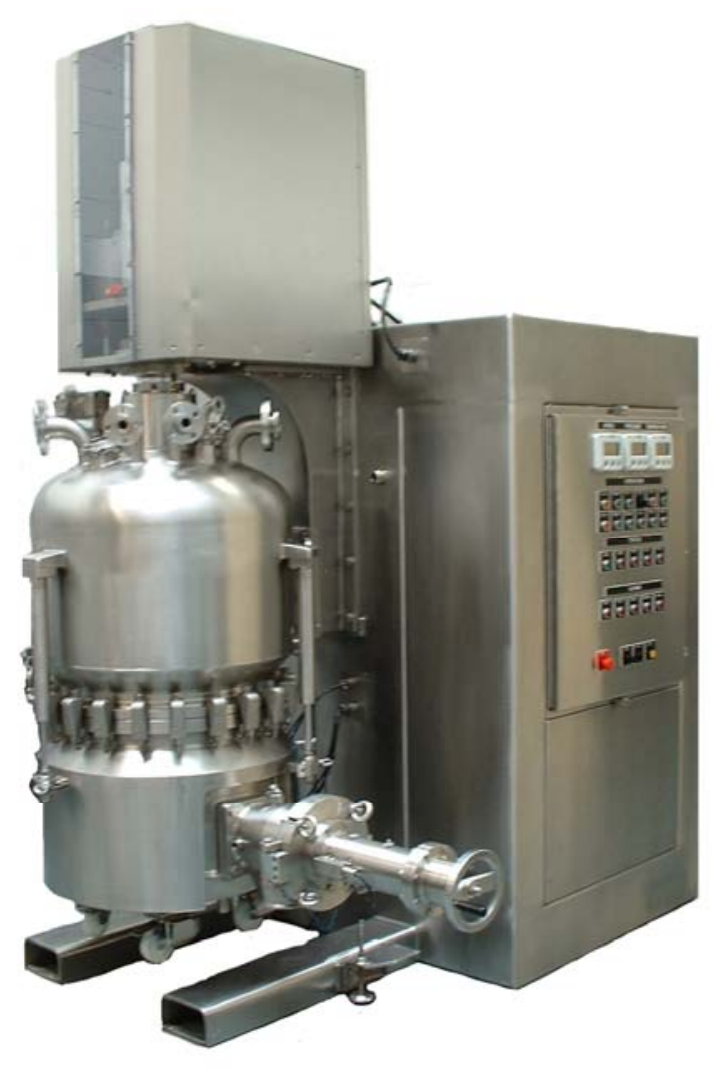

Figure 7. Nutsche Filter Dryer Purchased From Pfaudler

\section{Filter}

A 30 micron filter was incorporated between the 50 gallon reactor and the Nutsche Filter Dryer. This filter removes any potential contamination of particles from the reactor including silica powder on the surface of Levamelt ${ }^{\circledR} 1$ EVA pellets used as a starting material. This filter can become blinded and needed to be changed in order to get suitable flow rate when transferring to the Nutsche Filter Dryer. Typically, 2 to 3 filters were used per batch depending on the size of the filter (volume). The filters are manufactured by Enpro (formerly Pall, formerly US Filter) and then encapsulated by Ultra Optics in polypropylene. The filters used are Encapsulated, 30", $30 \mu \mathrm{m}$, DuoFine II Filter Element.

\section{Amount of Methanol}

The VCE product is dissolved in toluene in the reactor, and is recovered by precipitation into an excess of methanol in the Nutsche Filter Dryer. VCE dissolved in toluene is a viscous liquid with a consistency similar to honey or syrup and upon addition to an excess of methanol the VCE 
becomes a white crumb material capable of being filtered and washed with methanol. Initially, the 50 gallon batches were precipitated into 110 gallons of methanol in two steps. A 55 gallon drum of methanol was transferred into the Nutsche Filter Dryer and 1/2 of the contents of the reactor were precipitated into the vessel. The contents were allowed to stir until the VCE product was solid enough to be filtered. Then the solid white VCE crumb was filtered and washed with approximately 15-20 gallons of methanol. The first half of the VCE product was discharged from the Nutsche Filter Dryer and then the process was repeated a second time. It was taking a very long time for VCE product to solidify enough to be filtered. Prior to this, the VCE product had a slimy, soft consistency and quite a bit of the product would be lost through the filter. Therefore, the number of precipitations steps for a 50 gallon reaction was increased to three and the amount of methanol used for precipitation was increased to 165 gallons or three 55 gallon drums. Now for each precipitation step, one 55 gallon drum of methanol was loaded into the Nutsche Filter Dryer and $1 / 3$ of the reactor contents were precipitated into it. By increasing the amount of methanol, the VCE recovery step was much easier, took less time, and since material was not being pushed through the filter, the product yield increased.

\section{Drying Trays}

Once the VCE is filtered and discharged from the Nutsche Filter Dryer it is transferred into trays to remove any remaining toluene or methanol. The vacuum drying trays used previously formed sheets that were 12 " x 40 ". Because these sheets were large making it difficult to handle and package, the drying trays were redesigned to yield 8” x 12" VCE sheets. Burger \& Brown Engineering, Inc. designed and fabricated 20 drying trays to be used in the vacuum oven. The trays were 12" x 36 " in size with 4 sections for drying per tray, with Teflon spacers between each section. The maximum length including handles could not exceed 44"and the height could not to exceed $25 / 8$ " in order to fit into the existing vacuum oven. The trays were made out of aluminum and also included expanded aluminum covers. On the expanded aluminum covers a finer Teflon mesh material was used to further prevent foreign contaminants from falling on the melted VCE. Figure 8 show images of the drying trays with and without the expanded metal covers. A thin Teflon film is placed under the spacers to easily remove VCE sheets after drying is complete.
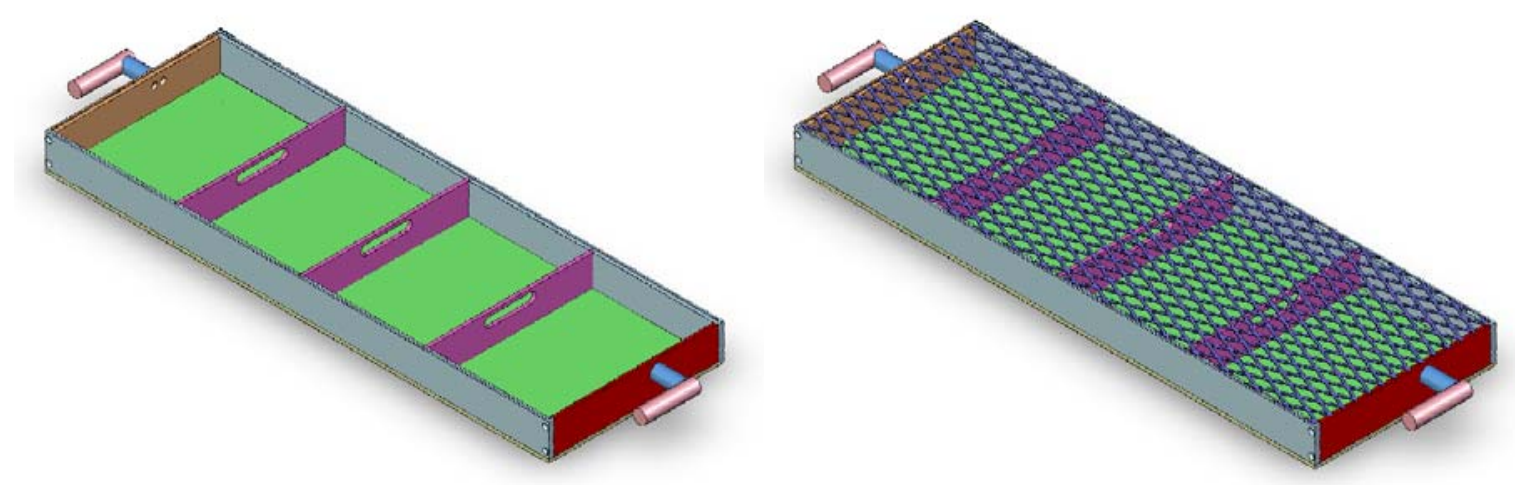

Figure 8. Drying Trays With and Without Expanded Metal Covers 


\section{Vacuum Drying Temperature and Time}

In the manufacturing process, wet VCE crumb is heated under vacuum to remove any remaining solvent and form solid uniform sheets by melting. A study was completed to determine the optimum time and temperature during the vacuum drying step. Higher temperatures results in a faster formation of the uniform sheets, however, there are higher risks associated with drying at higher temperatures. A balance must be obtained to provide enough heat to flow the material, but not too much which may cause degradation and undesired material property changes. One production lot, 6, had a melt viscosity of $339.3 \mathrm{~Pa}-\mathrm{s}$, which is below the minimum requirement of $400 \mathrm{~Pa}-\mathrm{s}$, and had to be scrapped. It should be noted that prior to the full production batch being dried, small samples from this lot were dried and upon testing had melt viscosity values of 510 Pa-s. It was theorized that this failed production batch was heated too long or too hot causing material degradation.

To determine the optimum temperature and time, previously manufactured VCE sheets were redissolved in toluene and re-precipitated into excess methanol and vacuum dried at 115, 125, and $133^{\circ} \mathrm{C}$. The trays were inspected daily and the number of days to form uniform sheets was recorded. In addition, the VCE samples were tested daily for changes in the melt viscosity. Figure 9 shows these melt viscosity changes for VCE heated at $115^{\circ} \mathrm{C}$. The melt viscosity is fairly unchanged up until 11 days after which a very linear decrease is observed. This consistent linear trend was used to estimate the failure at the minimum requirement. It was estimated to take 35 days at $115^{\circ} \mathrm{C}$ to reach failure based on this slope. Figure 10 plots the melt viscosity of VCE heated at $125^{\circ} \mathrm{C}$. The melt viscosity is trending downward, however, the slope is not as steep as used to estimate the failure at $115^{\circ} \mathrm{C}$. In addition, there does not appear to be consistent linear trend as observed previously. However, if viewing the $125^{\circ} \mathrm{C}$ trend line over the data set, it is estimated to take 128 days to reach failure. The final temperature evaluated was $133^{\circ} \mathrm{C}$ and the melt viscosity data as a function of number of days heated is shown in Figure 11. This data set may help explain the observed data for VCE heated at $125^{\circ} \mathrm{C}$. At $133^{\circ} \mathrm{C}$, VCE has an initial linear decrease in melt viscosity. If the decrease in melt viscosity that occurred over the first 3 days continued, the lower limit would have been reached by the $6^{\text {th }}$ day. However, at day 6 , an increase in melt viscosity is found. This increase continues linearly until the melt viscosity fails at the upper limit after 10 days. It is suspected that the increase in melt viscosity could be due to thermal cross linking. Therefore, there may be two competing mechanisms. One mechanism may be a thermal degradation which results in a decrease in melt viscosity. Conversely, at higher temperatures, thermal cross linking resulting in an increase in melt viscosity may occur with VCE. At $125^{\circ} \mathrm{C}$, the rate of both mechanisms may be fairly even and the change in melt viscosity is slow. Based on the data collected on this time/temperature study for the vacuum drying step, the recommended temperature is $245+/-15^{\circ} \mathrm{F}$ which correlates to 110 to $126.7^{\circ} \mathrm{C}$.

The final piece of information obtained from this study is the length of time it takes at each temperature to form solid uniform sheets. In Figure 12, the length of time to form a solid VCE sheet at various temperatures is shown. In addition, the time at the $110^{\circ} \mathrm{C}$ was estimated on this data shown and found form in approximately 8 days. The time needed to dry VCE is variable in the process routings, but should be within 5 to 8 days when heated in the specified temperature range of $245+/-15^{\circ} \mathrm{F}$. 


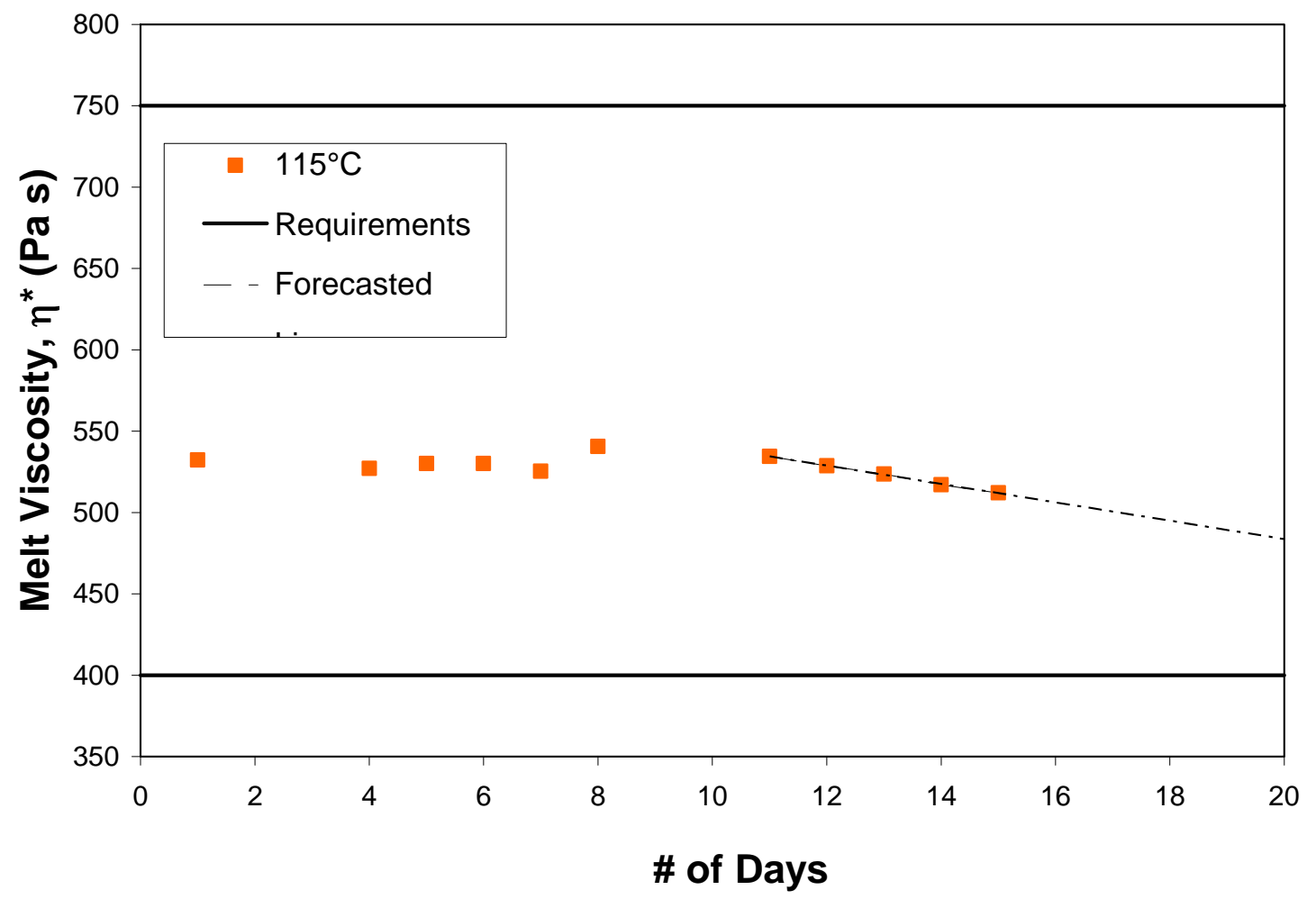

Figure 9. Plot of VCE's Melt Viscosity Over a Number of Days Heated at $115^{\circ} \mathrm{C}$

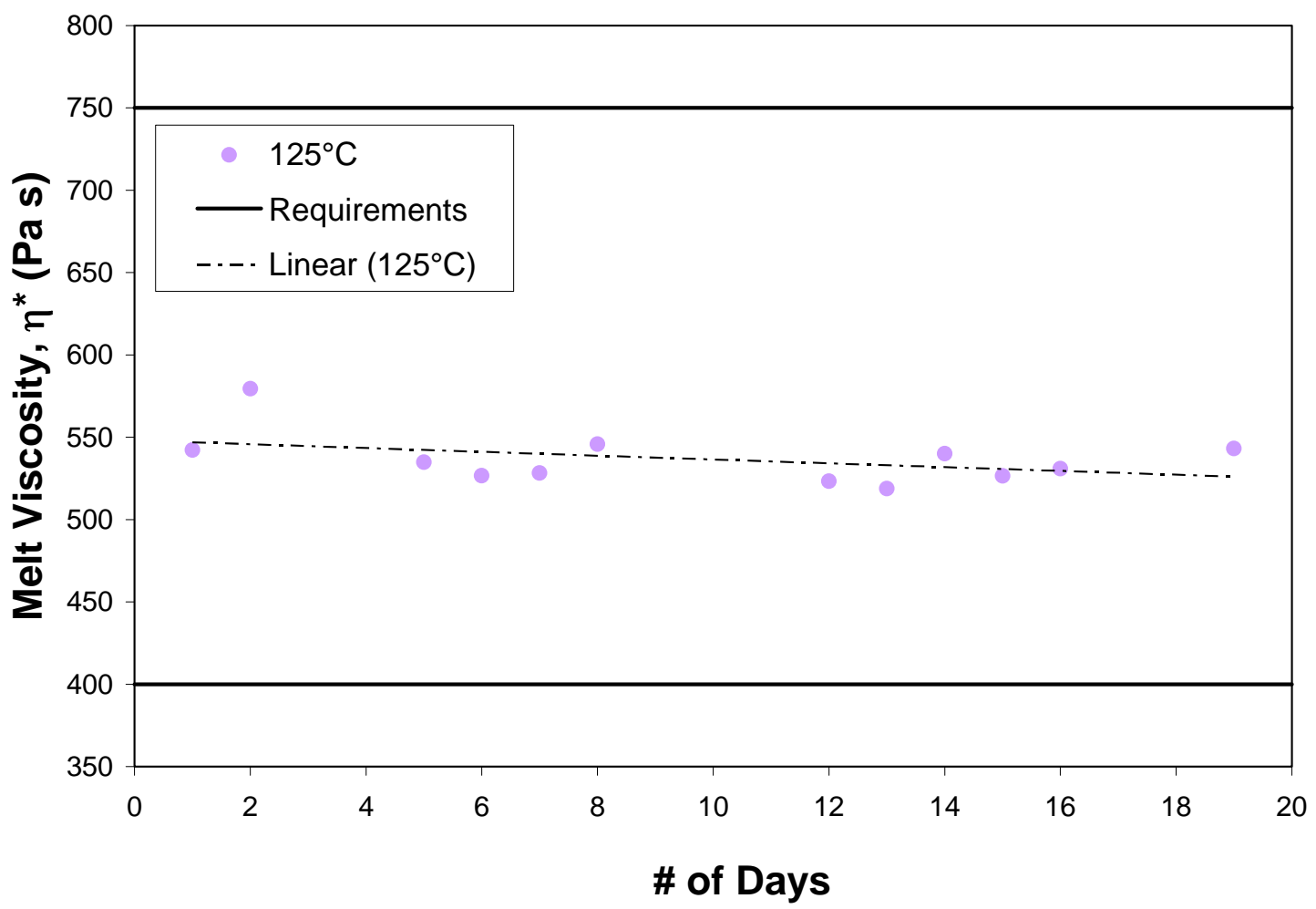

Figure 10. Plot of VCE's Melt Viscosity Over a Number of Days Heated at $125^{\circ} \mathrm{C}$ 


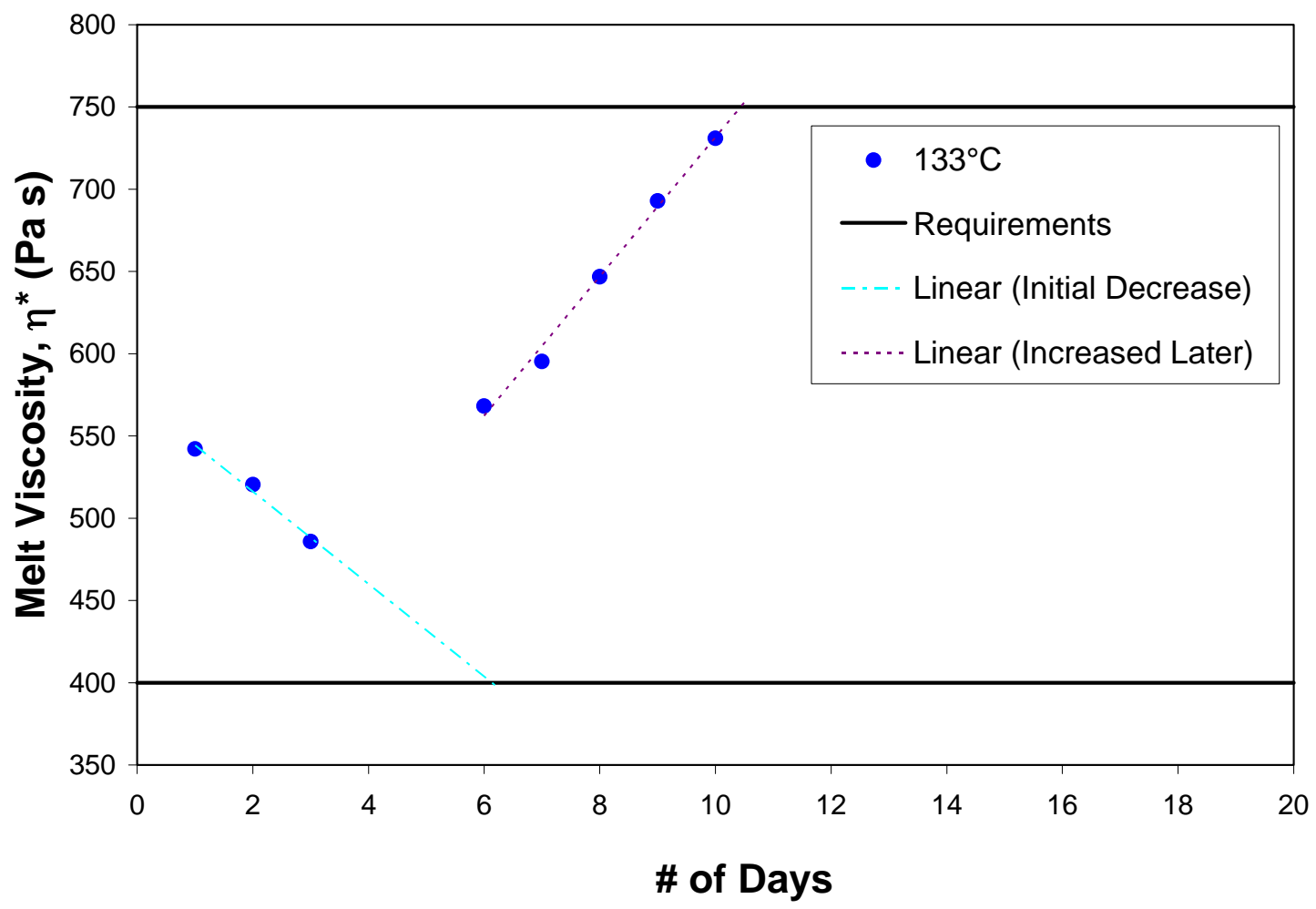

Figure 11. Plot of VCE's Melt Viscosity Over a Number of Days Heated at $133^{\circ} \mathrm{C}$

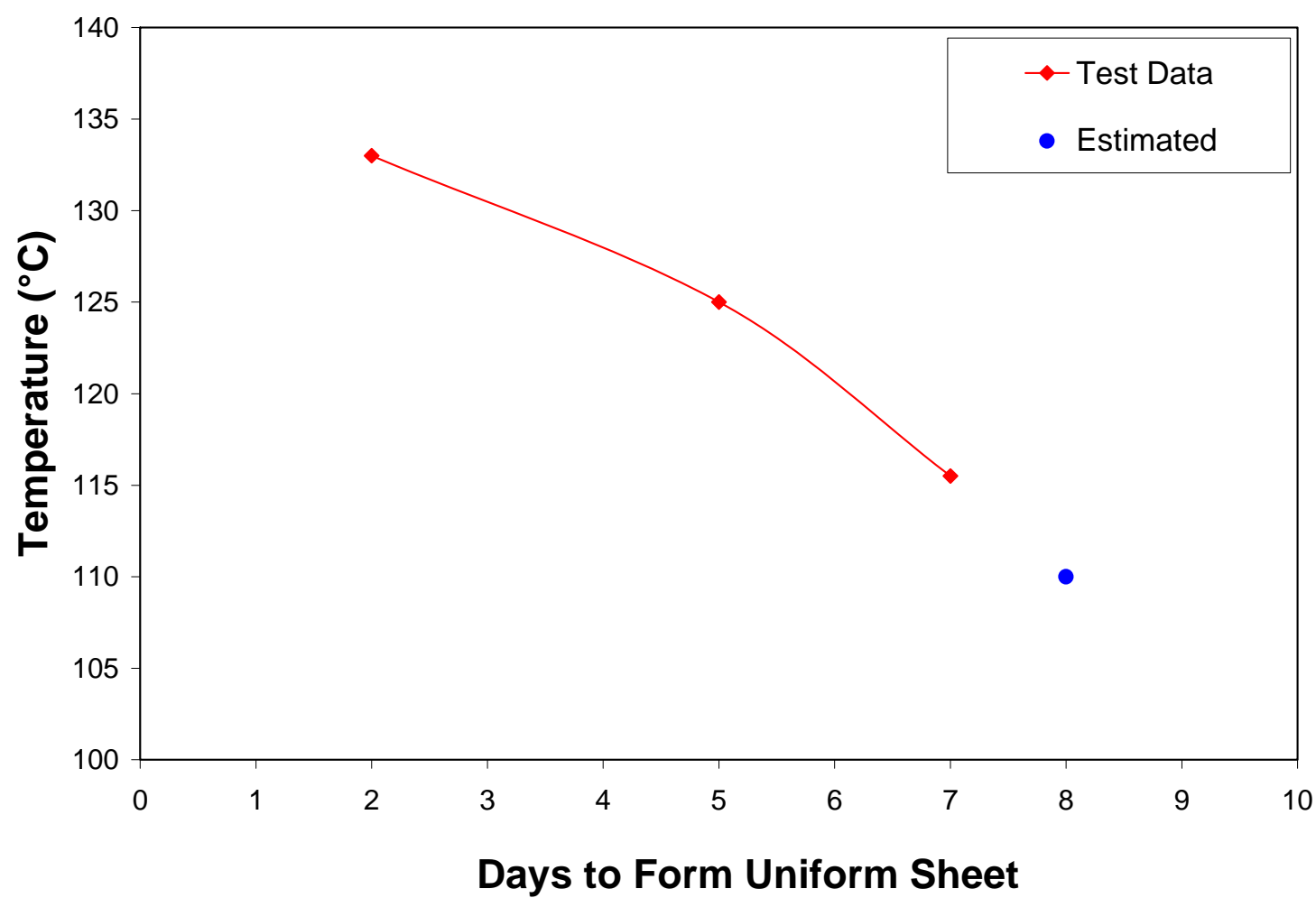

Figure 12. Plot Showing Length of Time to Form a Solid VCE Sheet at Various Temperatures 


\section{Accomplishments}

A scaled-up process was developed to manufacture poly(ethylene-co-vinyl acetate-co-vinyl alcohol) or VCE. A formulation of VCE was developed that met the material specification requirements and also improved the process ability during production in the final parts. In addition, the extent of reaction parameters was optimized in order to meet the specification in timely manner to enable VCE synthesis within a single work shift. Conversion rates based on different reaction temperatures were found for different reactor scales (2L, 4L, 15L, and 50 gallons). Incorporation of a Nutsche Filter Dryer, filters, changes to the amount of methanol used to precipitate, new drying trays, and optimization of the drying temperature and time led to a manufacturing process with improved worker safety, quality, yield, and efficiency. In addition, the reaction conditions were optimized in order to achieve a satisfactory conversion rate to enable production in a single work shift. Several equipment and process changes were made to yield a manufacturing process with improved product quality, yield, efficiency, and worker safety. 


\section{References}

1. E. A. Eastwood, VCE Replacement Development: Characterization of EVA Materials (Topical Report). UNCLASSIFIED. Federal Manufacturing \& Technologies: KCP-6136929, December 2004.

2. E. A. Eastwood, C. Densmore, VCE Replacement: Synthesis of VCEs with New Formulations (Topical Report). UNCLASSIFIED. Federal Manufacturing \& Technologies: KCP-613-8202, September 2006.

3. E. A. Eastwood, VCE Replacement: Curing Studies (Topical Report). UNCLASSIFIED. Federal Manufacturing \& Technologies: KCP-613-8161, July 2006.

4. Labouriau, A., Densmore, C., Meadows, K., Cordova, B., and Lewis, R., Characterization of VCE and Starting Materials: Part 1. LA-UR-06-5294. Los Alamos National Laboratory.

5. C. Densmore, E. Eastwood Characterization of VCE and Starting Materials: Part 2. LA-UR-06-6812. Los Alamos National Laboratory.

6. P. M. Wilson, Filled VCE (Ethylene Vinyl Acetate/Vinyl Alcohol Terpolymer) Materials and Processing Handbook (Topical Report). UNCLASSIFIED. Federal Manufacturing \& Technologies: KCP-613-6051, February 1998. 